\title{
SER Social
}

\author{
DESIGUALDADE, MUNDIALIZAÇÃO \\ E POLÍTICAS SOCIAIS CONTEMPORÂNEAS
}

Brasília, v. 22, n. 47, julho a dezembro de 2020

\section{Roda de conversa sobre redes e cooperação acadêmica internacional}

\section{Talk about networks and intermational academic cooperation}

Silvia Cristina Yannoulas ${ }^{1}$

Sophia Cunha Afonso ${ }^{2}$

O presente texto presta-se a resenhar a roda de conversa realizada com as professoras Adriana Rosa Clemente (Universidade de Buenos Aires-UBA, Argentina) e Silvia Cristina Yannoulas (Universidade de Brasília-UnB, Brasil), no Auditório da Faculdade de Direito da UnB, no dia 26 de setembro de 2019, e para participantes dos grupos de pesquisa do Programa de Pós-Graduação

\footnotetext{
1 Licenciada em Ciências da Educação pela Universidade de Buenos Aires (Argentina), mestre em Ciências Sociais pela Faculdade Latino-Americana de Ciências Sociais (Argentina), doutora em Sociologia pela Universidade de Brasília (Brasil). Pós-doutorado em Educação pela Universidade Federal de Minas Gerais (Brasil). Professora Adjunta 3. Coordenadora do grupo de pesquisa TEDis. E-mail: silviayannoulas@unb.br.

2 Graduação em Relações Internacionais e em Serviço Social, ambas pela Universidade de Brasília. Mestranda no Programa de Pós-Graduação em Política Social da Universidade de Brasília. Pesquisadora do grupo de pesquisa TEDis. E-mail: sophiaafonso8@ gmail.com.
} 
em Política Social da Universidade de Brasília (PPGPS/UnB; www. politicasocial.unb.br). A atividade foi promovida pelo Grupo de Pesquisa Trabalho, Educação e Discriminação-TEDis (www.tedis. unb.br), e desenvolvida no contexto do Seminário: Desigualdade, Mundialização e seus Efeitos sobre as Políticas Sociais Contemporâneas, organizado pelo PPGPS/UnB.

Silvia Yannoulas iniciou a roda de conversa apresentando o propósito da atividade, qual seja o de problematizar a internacionalização do ensino superior como uma tendência paradoxal: se é verdade que o processo pode ser positivo no sentido de ampliar o olhar sobre os objetos de pesquisa a partir da comparação e da divulgação dos seus resultados para além das fronteiras territoriais, a internacionalização também foi transformada em meta de avaliação de instituições e cursos de graduação e pós-graduação, e, nesse sentido, poderia constituir-se numa "armadilha".

Na roda foram apresentados elementos problematizadores extraídos da bibliografia (SILVA, 2017; FRANKLIN et al., 2017), das experiências comparadas de pesquisa das teses doutorais das expositoras (YANNOULAS, 1996; CLEMENTE, 2017), e da participação em redes de política social e áreas afins: Rede Estudos sobre o Trabalho Docente (Redestrado), criada, em 2009, no contexto do GT do Conselho Latino-Americano de Ciências Sociais (Clacso) e Red Ciudad y Universidad (conformada em 2015 no contexto de cooperação internacional entre as Universidades de Buenos Aires, a Nacional de Moreno e a de Brasília).

Primeiramente, foram comentadas as potencialidades da internacionalização no intuito de desenvolver estudos comparados. A comparação tem ampla tradição epistemológica, teórica e metodológica nas Ciências Sociais. Marx (1818-1883), Durkheim (18581917) e Weber (1864-1920) aplicaram o método comparativo entre períodos históricos ou entre culturas para construir seus respectivos objetos teóricos, realizando paralelamente reflexões epistemológicas sobre os estudos comparativos.

A comparação é uma ferramenta fundamental para compreender a forma como as nossas sociedades operacionalizam o gênero, 
a classe social e a raça, as três bases estruturantes da desigualdade social na América Latina. Permite, assim, perceber a pluralidade implícita em todo objeto de estudo, sua complexidade interna, e a controlar a autorreferência existencial de nossas categorias e teorias. O exercício consciente da descentralização não significa o abandono da bagagem cultural e teórica e, muito menos, do rigor científico; pelo contrário, implica no exercício de uma subjetividade consciente socialmente e comprometida politicamente que, em matéria da nossa ciência social contemporânea, são condições indispensáveis para a validação científica. Partindo dessa perspectiva, a comparação não é apenas necessária, mas desejável. (YANNOULAS, 1996).

Atualmente, a comparação internacional é facilitada pelo avanço das tecnologias contemporâneas, que permitem realizar estudos comparativos com maior precisão e menor custo. Mas devemos enfatizar que, embora a comparação internacional seja muito pertinente ao estudar questões fundamentais da política social (Estado, orçamento e financiamento, trabalho e emprego, migração, entre outras questões discutidas durante o seminário acima mencionado), não é em si mesma a solução para qualquer projeto de pesquisa ou intervenção.

Por que estudar um assunto de forma comparativa? A resposta não é única, mas podemos começar afirmando que a pergunta de pesquisa deve exigir um estudo comparativo para que seja respondida. Não se trata de comparar por comparar. Devemos ter uma inquietação gnosiológica que pressuponha um exercício comparado para ser resolvida. Sartori (1997) chama a atenção para o fato de que justapor dois ou mais países, estudando-os separadamente, não significa estudos comparativos. A garantia da realização de uma comparação substantiva seria que, entre esses dois casos, exista pelo menos um esquema conceitual unitário, uma análise aplicada a cada país com a mesma métrica, com base na mesma pergunta.

Para Ragin (1994), os objetivos da pesquisa comparativa seriam três: estudar a diversidade, interpretar diferentes significados culturais e/ou históricos e possibilitar o avanço teórico ao capturar estruturas universais que se repetem em todas as culturas e épocas. A pesquisa comparativa seria especialmente adequada para abordar problemáticas 
específicas de uma maneira complexa e múltipla, para a qual condições diversificadas e, às vezes, contraditórias são combinadas.

A comparação internacional pode ser utilizada para comparar no espaço (por exemplo, a implementação de políticas de transferência condicionada de renda, em diferentes países da América Latina, no mesmo momento histórico, com a intenção de descobrir as constantes de um modelo de política social e as especificidades ou particularidades dos casos em questão, como Adriana fez em sua tese sobre as configurações do Estado na Argentina e no Uruguai (CLEMENTE, 2017), no tempo (comparação de um único caso em diferentes momentos históricos, para pensar sobre a maneira pela qual certo modelo educacional era hegemônico na América Latina desde a colonização (à maneira de WEINBERG, 1995), ou misto, como procedeu Marx (1959), ao desenvolver sua análise e chegar à categoria de modo de produção.

Sobre as limitações dos processos de internacionalização em um mundo globalizado, a profa. Silvia apontou que os organismos internacionais (especialmente aqueles vinculados à livre circulação de capitais, produtos e pessoas como o FMI, a OCDE, o Banco Mundial, entre outras), têm um interesse especial em estudos comparativos e na internacionalização da ciência. Seus interesses levaram a privilegiar a realização de estudos comparados que permitiram os ranqueamentos de países e instituições, e que são utilizados para os propósitos do capitalismo em seu atual estágio globalizado: o aumento do lucro e a paralela diminuição dos chamados "gastos sociais". Dessa forma, desde o século XX, os instrumentos e indicadores comparados foram aprimorados, gerando uma compreensão mais homogênea dos problemas sociais entre os países, o que facilita a tarefa de políticos e investidores. Se ter informações detalhadas sobre várias questões nos "ajuda" como pesquisadores, não devemos ser ingênuos e pensar que essa homogeneização quantitativa forçada equilibra realidades tão diversas ou que as supostas "soluções" para a intervenção social que emergem dessa lógica podem ser eficazes e desejáveis, porque desconhecem as particularidades ou especificidades de cada caso, ou seja, levam ao oposto do objetivo da comparação. Assim, haveria um desvio do interesse original (comparação como ferramenta heurística) 
para um propósito político e lucrativo, dificultando a possibilidade de captar as nuances existentes nas definições-chave de categorias de conteúdo próprias da política social, tais como seguridade social.

Sobre as parcerias e a constituição de redes, as expositoras destacaram que exigem um grande dispêndio de recursos materiais e humanos. Criar e manter uma rede internacional em funcionamento exige paciência e tempo dedicados à construção de diversificados modos de interação, versatilidade nos contatos internacionais, domínio de línguas estrangeiras, disponibilidade de recursos tecnológicos visando agilizar a comunicação, disponibilidade de recursos financeiros e materiais para realização de encontros, entre outros elementos importantes. E, fundamentalmente, compromisso dos parceiros em manter a rede em funcionamento, inclusive nos momentos em que não há eventos ou encontros. Além disso, é necessário observar que as parcerias internacionais se conformam de maneira diferente nas ciências sociais e nas demais ciências (da vida e exatas), pois nessas áreas há toda uma discussão em torno de patentes e licenciamentos que é praticamente inexistente para as ciências humanas. Inclusive esse seria o fundamento da existência de recursos financeiros aplicados tão diferentemente entre as áreas: às ciências sociais e humanas não se aplicam na mesma medida que aos interesses capitalistas mundializados (farmacológicos, médicos, informáticos, entre outros).

Na hora do debate, a profa. Silvia manifestou sua preocupação com a recente experiência brasileira de democratização do ensino superior e um processo incipiente de (re)elitização, concomitante aos processos de internacionalização das universidades, pois para os estudantes de baixa renda resulta quase inviável atingir os patamares quanto à proficiência em idiomas exigidos pelas agências de fomento para acessar as bolsas de estudo. Também para as estudantes e docentes mulheres é mais difícil obter condições para o deslocamento para outros países em prol da realização de estudos comparados substantivos: maridos e filhos pesam de maneiras diferenciadas para eles e para elas.

A professora Adriana frisou o caráter essencialmente político do conhecimento sobre política social, por meio do exemplo da categoria de conteúdo "pobreza persistente". Os estudos compa- 
rados e a internacionalização permitem observar a universalidade da pobreza persistente como característica fundamental do capitalismo, em diferentes tempos e locais. Também é político o sentido da comparação internacional porque permite alimentar decisões em matéria de políticas públicas, sem ser pragmatista: trabalhar a ontologia dos problemas sociais, perguntar-se pelas causas. Entretanto, esse tipo de pesquisa leva tempo.

Para a construção de redes consistentes seria necessário dispor de informação sobre o que as instituições estão desenvolvendo, mas principalmente as redes deveriam ser "redes por afinidades", emergentes de pesquisadores em temas e abordagens comuns, que desde abaixo constroem articulações institucionais mais sólidas. Existe um valor intangível nas redes, que não pode ser necessariamente quantificado, mas que politicamente articula e fortalece os atores para além das fronteiras mais próximas.

A professora Lucélia Pereira, participante da roda, destacou também como elemento importante a utilidade do conhecimento comparado construído e o retorno à sociedade, a relevância do conhecimento comparado visando destacar quais são os temas de condensação que perpassam as ciências sociais e as agendas e políticas sociais em diferentes latitudes, especialmente na região latino-americana.

\section{Referências}

CLEMENTE, Adriana R. Reformas del Estado en América Latina y cambio en el paradigma de integración social en contextos de endeudamiento externo. Argentina y Uruguay en clave comparada (1990/2005). Tesis de Doctorado en Ciencias Sociales. Buenos Aires: Universidad de Buenos Aires. Fecha: 20/12/2017.

FRANKLIN, Luiza A.; ZUIN, Débora C.; EMMENDOERFER, Magnus. Processo de internacionalização do Ensino Superior e mobilidade acadêmica: Implicações para a gestão universitária no Brasil. Revista Internacional de Educação Superior (RIESup). Campinas-SP, v. 4, n. 1, p. 130-151, jan.-abr./2017. Disponível em: <https://periodicos.sbu.unicamp.br/ojs/index.php/riesup/article/ view/8650831>. Acesso em: 16/09/2019.

MARX, Karl. El capital. México: Fondo de Cultura Económico, 1959.

RAGIN, Charles. Constructing social research: the unity and diversity of method. Thosand Oaks-CA: Pine Forge Press. 1994 
SARTORI, Giovanni. A política: lógica e método nas ciências sociais. BrasíliaDF: UnB, 2. ed., 1997.

SILVA, Juremir M. da. Desafios da internacionalização acadêmica. In: MARTINS, Moisés de L. (org.). A internacionalização das comunidades lusófonas e iberoamericanas de Ciências Sociais e Humanas. Minho-PT: Húmus / Centro de Estudos de Comunicação e Sociedade, p. 179-192, 2017. Disponível em: <http:// www.lasics.uminho.pt/ojs/index.php/cecs_ebooks/article/view/2718/2626>.

WEINBERG, Gregorio. Modelos educativos en la historia de América Latina. Buenos Aires: UNESCO-CEPAL-PNUD; AZ, 1995.

YANNOULAS, Silvia C. Educar: una profesión de mujeres? Buenos Aires: Kapelusz, 1996. 